\begin{tabular}{llllllll} 
O P E R A T I O N S R E S E A R C H A N D D E C I S I O N S \\
\hline No. 3
\end{tabular}

DOI: $10.37190 /$ ord200305

\title{
USING INDIVIDUAL AND COMMON REFERENCE POINTS TO MEASURE THE PERFORMANCE OF ALTERNATIVES IN MULTIPLE CRITERIA EVALUATION
}

\author{
EWA ROSZKOWSKA ${ }^{1}$, MARZENA FILIPOWICZ-CHOMKO ${ }^{2 *}$, TOMASZ WACHOWICZ $^{3}$ \\ ${ }^{1}$ University of Bialystok, Warszawska 53, 15-062 Białystok, Poland \\ ${ }^{2}$ Bialystok University of Technology, Wiejska 45A, 15-351 Białystok, Poland \\ ${ }^{3}$ University of Economics in Katowice, ul. 1 Maja 50, 40-287 Katowice, Poland
}

\begin{abstract}
When evaluating or ordering alternatives concerning given multiple criteria, decision-makers often use aspiration and reservation levels for criteria, which allows them to define some reference alternatives that build a common framework for the evaluation. In this paper, new multiple criteria approach, called distances to aspiration reference points (DARP), is presented, which can be implemented in a specific evaluation or ranking problem when many different aspiration levels should be taken into consideration. One example of such problem is measuring sustainable development of countries or states within the Union. In DARP, to measure the performance of alternative (state), the notion of distances between alternative and individual or common aspiration reference points is used. To manage the problem of different reference points, a modified max-min normalisation technique is proposed. DARP application for measuring smart growth of the EU countries is conducted to demonstrate the effectiveness of the proposed method.
\end{abstract}

Keywords: reference points, aspiration level, distance measure, MCDM methods, smart growth

\section{Introduction}

Multiple criteria decision analysis is a vital branch of operations research. Multiple criteria decision-making (MCDM) methods are used to support numerous real-life rankings, sorting or selection of problems, where many alternatives need to be evaluated with respect to multiple conflicting criteria [37]. Significant achievements have been

*Corresponding author, email address: m.filipowicz@pb.edu.pl Received 14 November 2019, accepted 21 October 2020 
made in multiple criteria decision analysis from the early 1960s, and a variety of approaches and methods have been proposed since then [13,21].

Among many MCDM approaches, one group of techniques focuses on evaluating alternatives in comparison to others, i.e., evaluation of each alternative depends on the chosen reference points. Such a reference point can be either internal to the set of compared alternatives (i.e., defined exclusively by the combination of performances of all alternatives under consideration) or external. The external ones are simply the examples arbitrarily and subjectively defined by the decision-makers, analysts, or experts.

It is worth noting that the concept of reference points is consistent with Simon's [38] idea of satisfactory decision making where a decision-maker tends to have targets or goals in mind while proceeding toward a decision. We can distinguish two forms of reference or target points: aspiration points - considered as desirable levels of achievement, and reservation points, which represent levels of achievement that should be attained (if at all possible). Note that according to Simon, these references do not need to be extreme, i.e., while setting them, decision-maker may find a particular alternative either to exceed the aspiration limits or, on the contrary, not to fulfil the minima fixed by reservation reference [6]. In this study, we focus our attention on aspiration points only.

The use of the reference points in multiple objective optimisations was proposed by Wierzbicki [46]. The most popular methods applied to discrete decision-making problems that implement reference points are TOPSIS (technique for order preferences by similarity to ideal solution) [21], VIKOR (Serb. vlse kriterijumsk optimizacija i kompromisno resenje) [31], BIPOLAR [23], and taxonomic measure of development introduced by Hellwig [18]. The TOPSIS method [21] is based on the idea of selecting the alternatives which have the shortest distance from the positive ideal solution and the longest distance from the negative ideal solution at the same time. The positive ideal solution maximises the benefit criteria and minimises the cost ones, whereas the negative ideal solution maximises the cost criteria and minimises the benefit ones. The TOPSIS method is widely applied in MCDM field [5]. Opricovic [31] proposed the VIKOR method to find a compromise alternative. The VIKOR procedure $[8,47]$ uses the multiple criteria ranking index based on the measure of "closeness" to the "ideal" solution. Each alternative is evaluated concerning each criterion, and then the compromise ranking can be obtained while comparing the relative closeness measure to the ideal alternative. The BIPOLAR is an outranking method based on the notion of a synthesizing preference relational system in sorting and ranking problems [25]. Contrary to TOPSIS and VIKOR, it is not based on single reference alternatives (ideal and anti-ideal ones) but uses the concept of two bipolar sets of reference alternatives: a set of good (desirable), and bad (non-acceptable) solutions [25]. Modifications of BIPOLAR method are also proposed in the literature $[15,41]$, and some applications of the BIPOLAR method can also be found in $[14,16,24,40]$. Hellwig's technique was originally proposed in 1968 as a taxonomic method for international comparisons of economic development of countries [18]. This technique, very close to the TOPSIS procedure, allows to rank objects 
from the worst to the best, as based on their level of development in the area under evaluation. However, contrary to TOPSIS procedure, Hellwig's method used only the concept of ideal solution (pattern development). Some applications of Hellwig's method, in the literature called the Wroclaw Taxonomic Method [27], can be found in $[3,10,32,33,48]$.

The main goal of this paper is to present a new multiple criteria approach that could be used to evaluate and rank the alternatives concerning reference aspiration solution by implementing the notion of measuring distances called DARP (distances to aspiration reference points). However, in DARP we consider a specific context of decision making problem, in which the definition of such a reference aspiration point is not unequivocal, i.e., many different reference aspiration alternatives may be declared, employing different stakeholders in the problem and suggested to be applied to evaluation of some subgroups of alternatives or single alternatives, in extreme situations. This problem is quite common when different countries, states or other administrative units that comprise one union or organization are evaluated concerning their development performance $[12,29,30]$.

In such a case the global common targets may be defined by the central unit as well as the individual target set additionally by the constituent units. Therefore, in DARP we analyse the performance of alternatives by measuring their distance to the reference point that can be defined either externally (at an individual or common group level) or based on the internal structure of the alternatives. This measure is inspired by Hellwig's procedure of measuring distances to the pattern of development. However, in Hellwig's method the normalisation procedure is based on average and standard deviation (standard score) [18], while in our approach the reference points are used for min-max feature scaling, which allows us to address the issue of the existence of anti-ideal solution without determining the explicit distance to it. Additionally, by using various reference points, DARP allows also to conduct the comparative analysis of various evaluation schemas (rankings obtained) and conclude the quality of reference points fixed for these schemas. Note that by using DARP we implicitly assume that the decision maker's preferences are additive and preferentially independent among the criteria.

Another difference between DARP and TOPSIS or Hellwig's method is that DARP considers individual aspiration reference points to each alternative (or consequently, groups of alternatives), while classical TOPSIS and Hellwig's method use only the concept of the internal reference points, i.e., ideal solution maximises the benefit criteria and minimises the cost ones, whereas the anti-ideal solution maximises the cost criteria and minimises the benefit ones. Additionally, TOPSIS uses two reference points: ideal and anti-ideal, while Hellwig's procedure only one ideal reference point. This may be the advantage of Hellwig's method, yet it causes the problems with aggregating them into one scalar measure that can be easily interpreted by the decision-makers and stakeholders. DARP allows eliminating all these problems that may occur in TOPSIS and Hellwig's approaches. 
MCDM techniques are useful tools for evaluating sustainability development in different areas [20]. The proposed DARP method allows for the integration of the assessment of sustainable development goals with the target levels. We show the application of DARP method to measuring the smart growth of EU countries from the perspective of Strategy Europe 2020 in 2017, where two aspiration reference points were used, i.e., the targets were set up by individual countries as well as by EU. The comparative analysis of the results shows how the countries can vary in own goals and what is the quality of standards they introduce into their economies.

The remainder of this paper is structured as follows: the proposed new DARP approach along with some technical considerations are presented in Section 2. Section 3 provides an application of DARP in measuring smart growth of EU countries from the perspective Strategy Europe 2020 in the 2017. Section 4 concludes the paper.

\section{The measure of distances to aspiration reference points (DARP)}

Let us consider a multiple criteria evaluation problem, where $X=\left\{X_{1}, X_{2}, \ldots, X_{n}\right\}$ is the set of alternatives under consideration. Further, $C=\left\{C_{1}, C_{2}, \ldots, C_{m}\right\}$ is the set of criteria used for measuring the alternatives' actual performances, $X_{i}=\left[x_{i 1}, x_{i 2}, \ldots, x_{i m}\right]$ is the vector of consequences of $i$ th alternative, where $x_{i j}$ is the value of alternative $X_{i}$ concerning criterion $C_{j}, i=1, \ldots, n, j=1, \ldots, m$. Moreover, let $C=\left\{C_{1}, C_{2}, \ldots, C_{m}\right\}=B \cup C o$, where $B$ and $C o$ are the sets of benefit and cost criteria, respectively.

We introduce the notion of individual aspiration reference point $R P_{i}=\left[x_{i 1}^{+}, x_{i 2}^{+}, \ldots, x_{i m}^{+}\right]$ for $i$ th alternative, $i=1, \ldots, n$. The point $R P_{i}$ represents the aspiration values for criteria from the set $X$ defined by the constituent represented by alternative $X_{i}$, i.e., an ideal solution desired by decision-maker or stakeholder interested in or responsible for the alternative $X_{i}$. Let $R P=\left\{R P_{1}, \ldots, R P_{n}\right\}$ be the set of individual aspiration reference points.

DARP procedure requires performing the following computation steps:

Step 1. Defining the set of individual aspiration reference points $R P=\left\{R P_{1}, \ldots, R P_{n}\right\}$, where $R P_{i}=\left[x_{i 1}^{+}, x_{i 2}^{+}, \ldots, x_{i m}^{+}\right]$is the individual reference point for $i$ th alternative, $i=1, \ldots, n$.

Step 2. Defining the vector of weights $w=\left[w_{1}, \ldots, w_{m}\right]$, where $w_{j}>0, j=1, \ldots, m$ is the weight of $j$ th criterion, and

$$
\sum_{j=1}^{m} w_{j}=1
$$


Step 3a. Building the best performance alternative as an abstract point

$$
B P_{0}=\left[x_{1}^{+}, x_{2}^{+}, x_{m}^{+}\right]
$$

defined as

$$
x_{j}^{+}=\left\{\begin{array}{cl}
\max _{i} x_{i j} & \text { if } x_{i j} \in B \\
\min _{i} x_{i j} & \text { if } x_{i j} \in C o
\end{array}\right.
$$

Step 3b. Building the worst performance alternative as an abstract point

$$
W P_{0}=\left[x_{1}^{-}, x_{2}^{-}, \ldots, x_{m}^{-}\right]
$$

defined as

$$
x_{j}^{-}=\left\{\begin{array}{cl}
\underset{i}{\max x_{i j}} & \text { if } x_{i j} \in C o \\
\min _{i} x_{i j} & \text { if } x_{i j} \in B
\end{array}\right.
$$

Step 4. Building the normalised vector $\overline{\bar{X}}_{i}=\left[\overline{\bar{x}}_{i 1}, \ldots, \overline{\bar{x}}_{i m}\right]$ for $i$ th alternative, using the formula

$$
\overline{\bar{x}}_{i j}= \begin{cases}\frac{x_{i j}-x_{j}^{-}}{x_{i j}^{+}-x_{j}^{-}} & \text {if } 0 \leq \frac{x_{i j}-x_{j}^{-}}{x_{i j}^{+}-x_{j}^{-}}<1 \\ 1 & \text { otherwise }\end{cases}
$$

where $x_{i j}^{+}$is the individual aspiration reference point of $i$ th alternative for $j$ th criterion and $x_{j}^{-}$is defined using formula (3).

First, let us notice that if $x_{i j}^{+} \leq x_{j}^{-}$for benefit criterion or $x_{i j}^{+} \geq x_{j}^{-}$for cost criterion, then $\frac{x_{i j}-x_{j}^{-}}{x_{i j}^{+}-x^{-}}=1$. In this situation, we assume that the individual aspiration point for $x_{i j}$ is reached. However, such a situation seems to be unrealistic, but we have to bear in mind that the aspiration reference points are formulated subjectively, not necessarily by comparing with worth performance of all alternatives.

Moreover, let us observe that in the normalisation procedure we have to take into consideration two situations, for the benefit, and cost criteria, respectively.

For the benefit criterion, we have $x_{j}^{-} \leq x_{i j} \leq x_{j}^{+}$. 
If $x_{i j}^{+} \leq x_{j}^{-}$, then we assume that the individual aspiration point is reached, so $\overline{\bar{x}}_{i j}=1$.

If $x_{j}^{-}<x_{i j}^{+}$, then for $x_{j}^{-} \leq x_{i j} \leq x_{i j}^{+}$(i.e., the individual aspiration point is not reached) we have $0 \leq \frac{x_{i j}-x_{j}^{-}}{x_{i j}^{+}-x_{j}^{-}}<1$, so $\overline{\bar{x}}_{i j}=\frac{x_{i j}-x_{j}^{-}}{x_{i j}^{+}-x_{j}^{-}}$; for $x_{j}^{-}<x_{i j}^{+} \leq x_{i j}$ (i.e., the individual aspiration point is reached) we have $\frac{x_{i j}-x_{j}^{-}}{x_{i j}^{+}-x_{j}^{-}} \geq 1$ and in consequence $\overline{\bar{x}}_{i j}=1$.

Thus, we define:

$$
\overline{\bar{x}}_{i j}= \begin{cases}\frac{x_{i j}-x_{j}^{-}}{x_{i j}^{+}-x_{j}^{-}} & \text {if } 0 \leq \frac{x_{i j}-x_{j}^{-}}{x_{i j}^{+}-x_{j}^{-}}<1 \\ 1 & \text { otherwise }\end{cases}
$$

For cost criterion, we have $x_{j}^{+} \leq x_{i j} \leq x_{j}^{-}$.

If $x_{j}^{-} \leq x_{i j}^{+}$then we assumed the individual aspiration point is reached, so $\overline{\bar{x}}_{i j}=1$. If $x_{i j}^{+}<x_{j}^{-}$then for $x_{i j}^{+}<x_{i j}<x_{j}^{-}$(i.e., the individual aspiration point is not reached) we have $0 \leq \frac{x_{i j}-x_{j}^{-}}{x_{i j}^{+}-x_{j}^{-}}<1$, so $\overline{\bar{x}}_{i j}=\frac{x_{i j}-x_{j}^{-}}{x_{i j}^{+}-x_{j}^{-}}$; for $x_{i j} \leq x_{i j}^{+}<x_{j}^{-}$(i.e., the individual aspiration point is reached) we have $\frac{x_{i j}-x_{j}^{-}}{x_{i j}^{+}-x_{j}^{-}} \geq 1$ and in consequence $\overline{\bar{x}}_{i j}=1$.

Thus, we define

$$
\overline{\bar{x}}_{i j}= \begin{cases}\frac{x_{i j}-x_{j}^{-}}{x_{i j}^{+}-x_{j}^{-}} & \text {if } 0 \leq \frac{x_{i j}-x_{j}^{-}}{x_{i j}^{+}-x_{j}^{-}}<1 \\ 1 & \text { otherwise }\end{cases}
$$

Summing up the above two situations, formula (4) holds.

In general, if the individual reference point is reached by $x_{i j}$ then $\overline{\bar{x}}_{i j}=1$; if $x_{i j}$ is the worst performance of alternatives, but the reference point is not reached (i.e., $x_{j}^{-}=x_{i j}<x_{i j}^{+}$for benefit criterion or $x_{i j}^{+}<x_{i j}=x_{j}^{-}$for cost criterion), then $\overline{\bar{x}}_{i j}=0$, otherwise $\overline{\bar{x}}_{i j}=\frac{x_{i j}-x_{j}^{-}}{x_{i j}^{+}-x_{j}^{-}} \in(0,1)$. 
Step 5. Building the weighted normalised vector $\tilde{X}_{i}=\left[\tilde{x}_{i 1}, \ldots, \tilde{x}_{i m}\right]$ where

$$
\tilde{x}_{i j}=w_{j} \overline{\bar{x}}_{i j}
$$

for $i=1,2, \ldots, n$ and $j=1,2, \ldots, m$.

Step 6. Building the weighted normalised individual aspiration reference vector $\widetilde{R P}_{i}=\left[\tilde{x}_{i 1}^{+}, \tilde{x}_{i 2}^{+}, \ldots, \tilde{x}_{i m}^{+}\right]$where

$$
\tilde{x}_{i j}^{+}=w_{j} \overline{\bar{x}}_{i j}^{+}
$$

for $i=1,2, \ldots, n$ and $j=1,2, \ldots, m$.

Let us observe that

$$
\widetilde{R P}_{i}=\left[w_{1}, w_{2}, \ldots, w_{m}\right]
$$

Step 7. Calculating the distances $\left(d_{i 0}\right)$ of $i$ th alternative from individual aspiration reference $\left(R P_{i}\right)$ using the classical Euclidean distance measure:

$$
d_{i 0}\left(X_{i}, R P_{i}\right)=\sqrt{\sum_{j=1}^{m}\left(\tilde{x}_{i j}-w_{j}\right)^{2}}
$$

Let us observe that

$$
\max _{i} d_{i 0}\left(X_{i}, R P_{i}\right) \leq \sqrt{\sum_{j=1}^{m} w_{j}^{2}}
$$

Step 8. Calculating the DARP

For the $i$ th alternative, we compute

$$
\operatorname{DARP}\left(X_{i}, R P_{i}\right)=1-\frac{d_{i 0}\left(X_{i}, R P_{i}\right)}{d_{0}}
$$

where $d_{0}=\sqrt{\sum_{j=1}^{m} w_{j}^{2}}$.

Step 9. Ranking of alternatives according to descending $\operatorname{DARP}\left(X_{i}, R P_{i}\right)$.

It is worth noting that $\operatorname{DARP}\left(X_{i}, R P_{i}\right) \in[0,1]$. The higher synthetic measure value of $\operatorname{DARP}\left(X_{i}, R P_{i}\right)$, the higher position of a given alternative in the ranking is.

Note that if $w_{1}=\ldots=w_{m}$, then we can omit Step 5 of the procedure and use the following formula: 


$$
\operatorname{DARP}\left(X_{i}, R P_{i}\right)=1-\frac{d_{i 0}\left(X_{i}, R P_{i}\right)}{d_{0}}=1-\frac{\sqrt{\sum_{j=1}^{m}\left(\tilde{x}_{i j}-w_{j}\right)^{2}}}{\sqrt{\sum_{j=1}^{m} w_{j}^{2}}}=1-\frac{\sqrt{\sum_{j=1}^{m}\left(\overline{\bar{x}}_{i j}-1\right)^{2}}}{\sqrt{m}}
$$

Additionally, if $R P_{i}=R P_{k}$ for every $i, k=1,2, \ldots, n$, then we have a common aspiration reference point $R P_{0}=\left[x_{01}^{+}, x_{02}^{+}, \ldots, x_{0 m}^{+}\right]$. In particular, the special case of the common reference point is point $B P_{0}$ defined by formula (2) as the best performance alternative.

Note that from the viewpoint of comprehensive aggregation of single-criterion performances, DARP does not enable full compensation of some extra achievements of alternatives. It means that in the DARP procedure, we ignore the fact that value $x_{i j}$ can be outside the interval $\left[x_{j}^{-}, x_{i j}^{+}\right]$. Then, the potential surplus value of such $x_{i j}$ over $x_{i j}^{+}$or shortages to $x_{i j}^{-}$will not be compensated in any way with the option values of other criteria. It seems reasonable in the context of the evaluation problem that we consider, sustainability development may require the harmonic achievement of all targets simultaneously, and extra performance in one field may not alleviate negative effects for the economy or failures in other fields. However, if the extra surpluses should be considered, then the notion of quasi-compensation or full compensation may be introduced to DARP, as it was suggested previously to TOPSIS [35, 36].

Let us also notice that the main advantage of the proposed normalisation technique is that the data are scaled to a fixed range from 0 to 1 . This interprets normalised values more intuitive for decision-maker, as value 1 indicates if the individual aspiration point is reached, and 0 is the worst possible performance. Furthermore, it allows taking into consideration the reservation value at an early stage of data processing, and not to involve it into further determining of global score index (10). Hence, it makes the latter easier to understand and explain its mechanics to decision-maker, as no problems with handling distances to two reference points occur. Using other normalisation procedures, e.g., the $z$-score based on standard deviation and mean, leave both reference points to be aggregated (usually in a nonlinear way) in a form of single aggregate measure, and makes its interpretation equivocal (see problems for TOPSIS [42]).

Finally, note that out of many distance measures, the Euclidean distance was proposed in DARP in formula (8) to calculate the final performance of alternatives. We use the Euclidean distance as it was originally used in TOPSIS, and its applications to similar DM problems [34], for which our DARP is supposed to be an alternative decision aiding approach.

Having the general DARP procedure described above, some interesting properties may be observed and proved for it. 
Observation 1. Let $A_{i}=\left[x_{i 1}, x_{i 2}, \ldots, x_{i m}\right]$ be an alternative and $R P_{i}=\left[x_{i 1}^{+}, x_{i 2}^{+}, \ldots, x_{i m}^{+}\right]$ their reference point. Then,

a) $\operatorname{DARP}\left(X_{i}, R P_{i}\right)=1$ if and only if the following conditions are satisfied:

$x_{i j}^{+} \leq x_{j}^{-}$or $x_{i j} \geq x_{i j}^{+}$for every criterion $j \in B$,

$x_{j}^{-} \leq x_{i j}^{+}$or $x_{i j} \leq x_{i j}^{+}$for every criterion $j \in C o$.

b) $\operatorname{DARP}\left(X_{i}, R P_{i}\right)=0$ if and only if the following conditions are satisfied:

$x_{i j}=x_{j}^{-}<x_{i j}^{+}$for every criterion $j \in B$,

$x_{i j}^{+}<x_{i j}=x_{j}^{-}$for every criterion $j \in C o$,

where $B$ is the set of benefit criteria and $C o$ is the set of cost criteria.

Proof. The cases a) and b) easily follow the normalisation formulae (4) and (10).

Observation 2. Suppose that $X_{i}=\left[x_{i 1}, x_{i 2}, \ldots, x_{i m}\right]$ is an alternative from the set $X$ and $R P_{i}^{(a)}=\left[a_{i 1}^{+}, a_{i 2}^{+}, \ldots, a_{i m}^{+}\right], R P_{i}^{(b)}=\left[b_{i 1}^{+}, b_{i 2}^{+}, \ldots, b_{i m}^{+}\right]$are two reference points. If $a_{i j}^{+} \leq b_{i j}^{+}$for every criterion $j \in B$, and $a_{i j}^{+} \geq b_{i j}^{+}$for every criterion $j \in C o$, then $\operatorname{DARP}\left(X_{i}, R P_{i}^{(b)}\right)$ $\leq \operatorname{DARP}\left(X_{i}, R P_{i}^{(a)}\right)$, where $B$ and $C o$ is the set of benefit and cost criteria, respectively.

Proof. Suppose that $a_{i j}^{+} \leq b_{i j}^{+}$for every criterion $j \in B$ and $a_{i j}^{+} \geq b_{i j}^{+}$for every criterion $j \in C o$. Applying the normalisation formula (4), we obtain $\overline{\bar{x}}_{i j}^{R P_{i}^{(a)}} \geq \overline{\bar{x}}_{i j}^{R P_{i}^{(b)}}$, where $\overline{\bar{x}}_{i j}^{N}$ denotes the normalised value of $i$ th alternative for $j$ th criterion, determined concerning target $N$. Next, this clearly implies that $d_{i 0}\left(X_{i}, R P_{i}^{(a)}\right) \leq d_{i 0}\left(X_{i}, R P_{i}^{(b)}\right)$ and, in consequence, $\operatorname{DARP}\left(X_{i}, R P_{i}^{(b)}\right) \leq \operatorname{DARP}\left(X_{i}, R P_{i}^{(a)}\right)$.

\section{Application of DARP approach for measuring smart growth in the context of Strategy Europe 2020. An empirical study}

The MCDM methods having been mentioned in the Introduction are extensively used to evaluate sustainability development in various areas $[7,9,20]$. The authors are constantly contributing by developing new measurement tools and by defining new composite indicators $[2,26,29]$. However, despite numerous studies in the area of sustainability development measures, there are not many propositions of monitoring the assumed targets which are important in the context of the adopted 2030 Agenda for Sustainable Development [43]. The proposition of an analytical framework based on TOPSIS procedure, taking into consideration EU and/or national targets, are described 
in [34]. Here, we show that DARP measure also allows comparing the sustainable performance of EU countries on EU and national levels. The extended TOPSIS method [34] takes into consideration EU targets and/or national targets in building PIS and NIS, and next, the distances to ideal and anti-ideal patterns are calculated. This makes the comparison of two alternatives simultaneously more distant to PIS and NIS, but of different proportions, equivocal to [42]. The proposed DARP procedure simplifies the consideration of EU targets and/or national targets, and the interpretation of the results. Implementing the aspiration reference points (ideal patterns) only requires measuring the distances solely to those points. This is computationally simpler, but also allows decision-makers to easily comprehend the differences in global scores of alternatives, as in DARP clear dependencies between them can be proved. It does not require any sophisticated mathematical knowledge and formal skills (see Observation 2 in Section 2).

To respond to the existing needs and due to the methodological gap in the area of research on sustainable development, we demonstrate how the DARP method measures the smart growth in 2017 from the perspective of Europe 2020 Strategy. The additional advantages of DARP method, which enables setting different aspiration levels, will be shown by considering three evaluation setups that take into consideration: (1) the best performance of the alternatives (DARP1) - the best EU country in the area, (2) the EU targets (DARP2), and (3) national targets (DARP3).

\subsection{Problem description and the source of data}

The main aim of the Europe 2020 Strategy, introduced by the European Commission (EC) in 2010 [11], was to create a solid foundation for development based on three mutually reinforcing priorities:

- smart growth: developing an economy based on knowledge and innovation,

- sustainable growth: promoting a more resource-efficient, greener and more competitive economy,

- inclusive growth: fostering a high-employment economy delivering social and territorial cohesion [11, p. 7].

To monitor the implementation of the strategy 2020 by each member state, in 2010 the Commission proposed the following EU headline targets [11]:

- $75 \%$ of the population aged 20-64 should be employed,

- $3 \%$ of the EU GDP should be invested in R \& D,

- the " $20 / 20 / 20$ " climate/energy targets should be met (including an increase to $30 \%$ of emissions reduction if the conditions are right),

- the share of early school leavers should be under $10 \%$ and at least $40 \%$ of the younger generation should have a tertiary degree,

- 20 million fewer people should be at risk of poverty. 
Table 1. The list of smart growth indicators and EU targets

\begin{tabular}{|c|l|r|}
\hline No. & \multicolumn{1}{|c|}{ Indicator } & EU target \\
\hline$C_{1}$ & Gross domestic expenditure on R\&D (GERD) - per cent of the gross domestic product $(B)$ & at least 3\% \\
\hline$C_{2}$ & Early leavers from education and training - per cent of the population aged 18-24 $(\mathrm{Co})$ & below 10\% \\
\hline$C_{3}$ & Tertiary educational attainment - per cent of the population aged 30-34 $(B)$ & at least 40\% \\
\hline
\end{tabular}

Source: Eurostat; $B$ stands for benefit criterion, $C o$ for cost criterion.

Table 2. The data of the $27 \mathrm{EU}$ countries and national targets in 2017

\begin{tabular}{|c|c|c|c|c|c|c|}
\hline Country & $C_{1}$ & $\begin{array}{l}\text { National } \\
\text { target } C_{1}\end{array}$ & $C_{2}$ & $\begin{array}{l}\text { National } \\
\text { target } C_{2}\end{array}$ & $C_{3}$ & $\begin{array}{l}\text { National } \\
\text { target } C_{3}\end{array}$ \\
\hline Austria & $3.16^{*}$ & 3.76 & $7.4^{*}$ & 9.5 & $40.8^{*}$ & 38 \\
\hline Belgium & 2.58 & 3 & $8.9^{*}$ & 9.5 & $45.9^{*}$ & 47 \\
\hline Bulgaria & 0.75 & 1.5 & 12.7 & 11 & 32.8 & 36 \\
\hline Croatia & 0.86 & 1.4 & $3.1^{*}$ & 4 & 28.7 & 35 \\
\hline Cyprus & 0.56 & 0.5 & $8,5^{*}$ & 10 & $55.9^{*}$ & 46 \\
\hline Czechia & 1.79 & 1 & $6.7^{*}$ & 5.5 & 34.2 & 32 \\
\hline Denmark & $3.05^{*}$ & 3 & $8.8^{*}$ & 10 & $48.8^{*}$ & 40 \\
\hline Estonia & 1.29 & 3 & 10.8 & 9.5 & $48.4^{*}$ & 40 \\
\hline Finland & 2.76 & 4 & $8.2^{*}$ & 8 & $44.6^{*}$ & 42 \\
\hline France & 2.19 & 3 & $8.9^{*}$ & 9.5 & $44.3^{*}$ & 50 \\
\hline Germany & $3.02^{*}$ & 3 & 10.1 & 10 & 34 & 42 \\
\hline Greece & 1.13 & 1.2 & $6^{*}$ & 10 & $43.7^{*}$ & 32 \\
\hline Hungary & 1.35 & 1.8 & 12.5 & 10 & 32.1 & 34 \\
\hline Ireland & 1.05 & 2 & $5^{*}$ & 8 & $54.5^{*}$ & 60 \\
\hline Italy & 1.35 & 1.53 & 14 & 16 & 26.9 & 26 \\
\hline Latvia & 0.51 & 1.5 & $8.6^{*}$ & 10 & $43.8^{*}$ & 34 \\
\hline Lithuania & 0.89 & 1.9 & $5.4^{*}$ & 9 & $58^{*}$ & 48.7 \\
\hline Luxembourg & 1.26 & 2.3 & $7.3^{*}$ & 10 & $52.7^{*}$ & 66 \\
\hline Malta & 0.54 & 2 & 17.7 & 10 & 33.5 & 33 \\
\hline Netherlands & 1.99 & 2.5 & $7.1^{*}$ & 8 & $47.9^{*}$ & 40 \\
\hline Poland & 1.03 & 1.7 & $5^{*}$ & 4.5 & $45.7^{*}$ & 45 \\
\hline Portugal & 1.33 & 2.7 & 12.6 & 10 & 33.5 & 40 \\
\hline Romania & 0.5 & 2 & 18.1 & 11.3 & 26.3 & 26.7 \\
\hline Slovakia & 0.88 & 1.2 & $9.3^{*}$ & 6 & 34.3 & 40 \\
\hline Slovenia & 1.86 & 3 & $4.3^{*}$ & 5 & $46.4^{*}$ & 40 \\
\hline Spain & 1.2 & 2 & 18.3 & 15 & $41.2^{*}$ & 44 \\
\hline Sweden & $3.4^{*}$ & 4 & $7.7^{*}$ & 7 & $51.3^{*}$ & 45 \\
\hline Max & 3.4 & 4 & 18.3 & 16 & 58 & 66 \\
\hline Min & 0.5 & 0.5 & 3.1 & 4 & 26.3 & 26 \\
\hline Mean value & 1.57 & 2.24 & 9.37 & 9.12 & 41.86 & 40.83 \\
\hline Standard deviation & 0.90 & 0.92 & 4.10 & 2.73 & 9.11 & 8.90 \\
\hline Variability coefficient & 0.57 & 0.41 & 0.44 & 0.30 & 0.22 & 0.22 \\
\hline
\end{tabular}

${ }^{*} \mathrm{EU}$ target is fulfilled. 
To ensure that each country tailors the Europe 2020 strategy to its situation, the Commission proposed that EU goals should be translated into national targets. Therefore, each EU country can check its progress towards each goal.

Specifically, to evaluate the progress of EU countries in achieving the smart growth and, this way, the extent of implementation of the Europe 2020 strategy, the set of three indicators is used, as well as the EU targets identified in this strategy, and national targets accepted by the member states. The list of these indicators, with EU targets used in the analysis, collected in the database of Eurostat, are presented in Table 1. The comprehensive definitions of indicators can be found in Eurostat 2018.

The set of data for the $27 \mathrm{EU}$ countries in 2017 consisting of three indicators and marked by symbols $C_{1}-C_{3}$, together with national targets, are presented in Table 2 . All three indicators were statistically verified. They satisfy three formal statistical criteria: high level of variation, high information value, and low level of correlation [19]. We also assume that achieving all single-criteria targets represented by each indicator (defined by EU or national) are so important that we cannot take into consideration the possibility of between-criteria compensation of performances within each alternative.

National targets for gross domestic expenditure on $\mathrm{R} \& \mathrm{D}$ ranges from $0.5 \%$ for Romania to $3.4 \%$ for Sweden, for early leavers from education and training from 3.1\% for Croatia to $18.3 \%$ for Spain, and tertiary educational attainment from 26.3 for Romania to 58 for Lithuania in 2017. Table 2 shows that in 2017, four countries already achieved their EU targets for $C_{1}$, eighteen for $C_{2}$, and seventeen for $C_{3}$.

\subsection{Results and discussion}

In our analysis of the countries' performances, the same weights for all indicators are adopted. Table 3 summarises the values of synthetic measures and rankings of the EU countries obtained from DARP procedure based on: (1) internal reference point $(R P 1)$, i.e., the best observed performance in the set of the alternatives; (2) externally defined common reference point $(R P 2)$, i.e., EU targets, and (3) externally defined individual reference point $(R P 3)$, i.e., national targets all with equal weights. For simplicity, we refer to $\operatorname{DARP}\left(X_{i}, R P k\right)$ values obtained for all these three reference points as $D k\left(X_{i}\right)$ for $k \in\{1,2,3\}$.

While analysing positions of EU countries in the overall classification obtained from different reference points ( $D k\left(X_{i}\right)$ for $k \in\{1,2,3\}$ ), one may observe that rank orders of some EU countries change. The biggest differences in values and rankings are obtained for $D 1$ and $D 3$. This is confirmed by the Pearson's correlation coefficients between three evaluations schemas used: $r(D 1, D 2)=0.954, r(D 1, D 3)=0.725, r(D 2, D 3)=0.730$, and all of them are statistically significant $(p<0.05)$. This shows that the EU targets (external reference points) quite well reflect the high internal diversity of EU countries with respect to smart growth. None of them, however, can reflect the internal economic 
conditions and possibilities of the countries in implementing the abstract global goals. This indicates the possibility of misinterpreting the real performance of the countries and their engagement in implementing the goals using the global target.

Table 3. DARP values and rank orders of EU countries

\begin{tabular}{|l|c|c|c|c|c|c|c|c|c|}
\hline \multicolumn{1}{|c|}{ Country } & $\begin{array}{c}D 1 \\
\text { (for } R P 1 \text { ) }\end{array}$ & Rank & $\begin{array}{c}D 2 \\
\text { (for } R P 2)\end{array}$ & Rank & $\begin{array}{c}D 3 \\
\text { (for } R P 3)\end{array}$ & Rank & $D 2-D 1$ & $D 3-D 1$ & $D 3-D 2$ \\
\hline Austria & 0.643 & 5 & 1 & 1 & 0.894 & 8 & 0.357 & 0.251 & -0.106 \\
\hline Belgium & 0.648 & 4 & 0.903 & 5 & 0.898 & 6 & 0.255 & 0.250 & -0.005 \\
\hline Bulgaria & 0.211 & 24 & 0.370 & 22 & 0.508 & 22 & 0.158 & 0.297 & 0.139 \\
\hline Croatia & 0.265 & 22 & 0.314 & 23 & 0.457 & 23 & 0.049 & 0.192 & 0.143 \\
\hline Cyprus & 0.397 & 17 & 0.437 & 20 & 1 & 1 & 0.039 & 0.603 & 0.563 \\
\hline Czechia & 0.444 & 16 & 0.629 & 10 & 0.946 & 3 & 0.185 & 0.502 & 0.317 \\
\hline Denmark & 0.717 & 2 & 1 & 1 & 1 & 1 & 0.283 & 0.283 & 0 \\
\hline Estonia & 0.459 & 15 & 0.601 & 11 & 0.596 & 19 & 0.142 & 0.137 & -0.005 \\
\hline Finland & 0.663 & 3 & 0.945 & 4 & 0.795 & 10 & 0.281 & 0.132 & -0.149 \\
\hline France & 0.589 & 8 & 0.813 & 6 & 0.767 & 11 & 0.224 & 0.178 & -0.046 \\
\hline Germany & 0.483 & 12 & 0.747 & 8 & 0.706 & 13 & 0.264 & 0.223 & -0.041 \\
\hline Greece & 0.467 & 14 & 0.568 & 13 & 0.942 & 4 & 0.101 & 0.475 & 0.374 \\
\hline Hungary & 0.281 & 21 & 0.465 & 18 & 0.699 & 14 & 0.184 & 0.418 & 0.234 \\
\hline Ireland & 0.522 & 10 & 0.550 & 14 & 0.622 & 16 & 0.027 & 0.100 & 0.073 \\
\hline Italy & 0.188 & 25 & 0.274 & 25 & 0.899 & 5 & 0.085 & 0.711 & 0.625 \\
\hline Latvia & 0.335 & 18 & 0.425 & 21 & 0.428 & 24 & 0.089 & 0.093 & 0.003 \\
\hline Lithuania & 0.493 & 11 & 0.513 & 16 & 0.583 & 20 & 0.020 & 0.091 & 0.071 \\
\hline Luxembourg & 0.535 & 9 & 0.598 & 12 & 0.614 & 17 & 0.063 & 0.079 & 0.016 \\
\hline Malta & 0.088 & 26 & 0.173 & 26 & 0.224 & 26 & 0.084 & 0.135 & 0.051 \\
\hline Netherlands & 0.632 & 6 & 0.767 & 7 & 0.853 & 9 & 0.135 & 0.221 & 0.086 \\
\hline Poland & 0.473 & 13 & 0.545 & 15 & 0.677 & 15 & 0.072 & 0.204 & 0.132 \\
\hline Portugal & 0.293 & 20 & 0.494 & 17 & 0.513 & 21 & 0.201 & 0.220 & 0.019 \\
\hline Romania & 0.004 & 27 & 0.008 & 27 & 0.009 & 27 & 0.004 & 0.005 & 0.001 \\
\hline Slovakia & 0.298 & 19 & 0.455 & 19 & 0.611 & 18 & 0.157 & 0.313 & 0.156 \\
\hline Slovenia & 0.625 & 7 & 0.737 & 9 & 0.737 & 12 & 0.112 & 0.112 & 0 \\
\hline Spain & 0.213 & 23 & 0.289 & 24 & 0.339 & 25 & 0.075 & 0.126 & 0.050 \\
\hline Sweden & 0.787 & 1 & 1 & 1 & 0.895 & 7 & 0.213 & 0.108 & -0.105 \\
\hline
\end{tabular}

A comparison of differences in the countries' performances determined according to different reference points and their diversity can be better illustrated by using the radial line graph (see Fig. 1).

Let us recall that $R P 1$ and $R P 2$ are based on common reference points, internal and external, respectively. More precisely, $R P 1=[3.4,3.1,58]$ (the best performance of the alternatives) and $R P 2=[3,10,40]$ (EU targets). From Observation 2, we know that for every country $D 1\left(X_{i}\right) \leq D 2\left(X_{i}\right)$ (see also Fig. 1). However, it does not assure that the rankings built as based on $D 1$ and $D 2$ will be similar. In fact, only four countries did not 
change their position and ten of them improved their positions (assigned better ranks, according to $D 2$ ). The biggest difference in position in the rankings based on $D 1$ and $D 2$ was observed for Czechia, from 16th position in $D 1$ to 10 th position in $D 2$, and Lithuania, which lost 5 ranks (from 11th position in $D 1$ to 16 th position in $D 2$ ). All rankings indicated Denmark (second in $D 1$ and first in $D 2$ and $D 3$ ) as the country with the highest level of implementation of smart growth in the perspective of EU and national targets. In the case of ranking obtained by $D 2$, the highest positions are also occupied by Austria and Sweden. These two countries reached all EU targets, so from formula (4) we have $D 2($ Sweden) $=D 2$ (Austria) $=1$ (see also Observation 1).

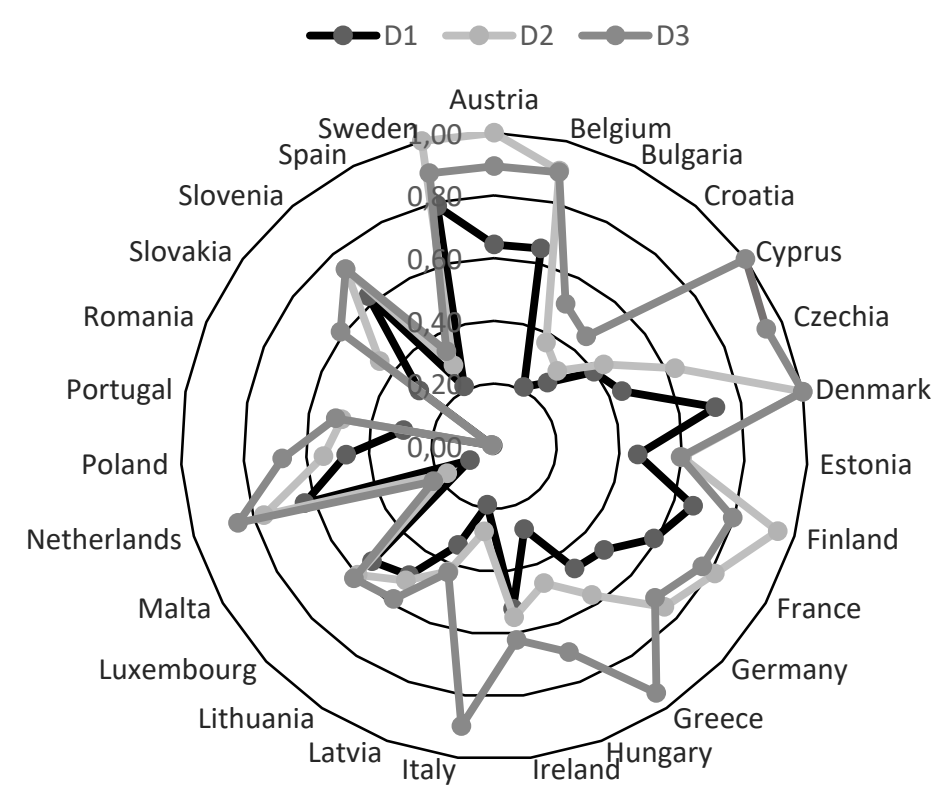

Fig. 1. Comparison of rankings based on $D 1, D 2$ and $D 3$

Bearing in mind the D3-based ranking, the first positions are occupied again by Denmark, but also by Cyprus. These two countries achieved all national targets and by formula (4) we have D3(Denmark) $=D 3$ (Cyprus) $=1$. Moreover, for Denmark, all national targets are EU targets, so D2(Denmark) $=1$. Comparing positions for Cyprus obtained by $D 2$ and $D 3$, we get the biggest change from the 20th position to the 1st position. Such a significant difference in positions was caused by particularly low national targets adopted by Cyprus (their values in the case of target $C_{1}$ and $C_{3}$ are equal to 0.5 and 46 , respectively). 
What is interesting, individual aspiration reference point for criterion $C_{1}$ assumed by Cyprus is equal to minimum values of criterion $C_{1}$ (see Table 2). Moreover, the individual aspiration reference point of Italy for criterion $C_{3}$ occurs to be even smaller than the minimum value for criterion $C_{3}$ (see Table 2). For both cases, we assume that those countries reached the aspiration point with respect to those criteria, so from formula (4) the normalised values of Cyprus and Italy with respect to criteria $C_{1}$ and $C_{3}$ take the value one. This shows the robustness of formula (4) irrespective of the situation. Naturally, the lower assumed national targets, the higher position in the ranking based on $D 3$ in comparison with the one obtained from D2 (see positions of such countries as Czechia, Greece, and Italy). On the other hand, the ambitiously assumed national targets can influence lower positions in the ranking. It happens in the case of Finland and Sweden. Note, however, that the external individual targets should not be considered as the objective measure of between-countries "comparable" performance, but are rather as indicators of their individual country-specific improvement and could be used in selfevaluation, resetting the targets for the future, and control for the pace of implementing the internal development strategy $[12,28]$.

Despite the fact the conditions of Observation 2 are not satisfied for each country (see $R P 1$ and $R P 3$ for Austria, Finland, Ireland, Luxembourg, Sweden), for all countries the condition $D 1 \leq D 3$ holds. On the other hand, it confirms the assumption of compensatory MCDM, in which some surpluses over the targets may not compensate for the shortages in others as they are not enough significant. The fact that $D 1 \leq D 3$ shows the diversity in development of EU countries and that no country can be considered as an ideal leader, since there are always others that outperform it with respect to at least one criterion. Sweden seems to be objectively the leader, but it still is not the best from the viewpoint of maximising all single-criteria performances. A comparison of $D 2$ and $D 3$ values brings interesting findings. It shows that for some countries the difference $D 3-D 2$ is positive, and for others negative. For two countries it is equal to zero, i.e., for Denmark and for Slovenia. We can say that if $D 3-D 2>0$, then the country had to set at least one individual target lower than the EU target. Consequently, if $D 3-D 2<0$, then at least one individual target is higher than EUs one.

The comparison of $D 2$ and $D 3$ results shows, to some extent, how ambitious the targets were set up by the countries with respect to the EU ones. Naturally, the contextual or economy-dependent issues may not allow different countries to set up the $R P 3$ equally high, yet the general attitude to EU postulates may be analysed and verified with some objective performances. For instance, Sweden fulfilled all the EU requirements at the top levels (quasi-compensatory nature of DARP measure does not allow to consider, if they were exceeded), hence $D 2($ Sweden $)=1$. Yet, this must have not been Sweden's idea to consider these levels as sufficient, hence it individually set up higher targets (RP3), which - unfortunately - was unable to reach (dark grey line below the light grey in Fig. 1). The need for self-improvement of Sweden is emphasised by the highest $D 1$ level, which shows that it is the best $(D 1)$ and good enough $(D 2)$, but still willing to improve. 
On the other hand, looking at countries like Cyprus and Greece, we can see that their targets were significantly worse than the EU ones. This is shown by a huge discrepancy between grey and light grey lines (D2 and D3) in Fig. 1. It shows, on the one hand, that these countries were able to achieve their individual goals, yet since these goals were far from the EU ones, we cannot compare these achievements to the achievements of other countries for which $R P 3$ significantly exceeded $R P 2$. This indicates the problems for unambiguous interpretation of real achievements of the countries and the need for a universal measure of such achievements that could be used in the betweencountry comparison.

\section{Conclusion and further research}

In this paper, two main scientific aims have been posed. One of them was to develop a new method, called DARP, which would allow to handle multiple criteria evaluation problem using an intuitive notion of distances, when individual and common aspiration reference points are considered (internal vs. external). This method can be used to rank a finite set of alternatives in order of their distance to a given aspiration reference point. Distances may or may not be weighted, reflecting the difference in importance of the evaluation criteria. To make the distances comparable, a normalisation operation was needed to transform the criteria scales into a common scale. In the proposed DARP method, the modification of min-max normalisation is used, which can effectively represent the normalisation values due to the considered form of reference points. Let us notice that, in general, the normalisation methods can result in different scores or rankings [17, 22, 39]. Finally, in DARP procedure, the relationship between alternatives and their reference points is considered in the process of decision making, which is more grounded in reality.

Let us emphasise that the major advantage of DARP over TOPSIS and VIKOR, which are similarly used to score alternatives in comparison to reference points, is that it allows one to take into consideration both individually defined or externally-bounded aspiration and reservation levels. Furthermore, it simplifies the calculation, as no advances aggregate criterion is introduced in the process, which simultaneously makes it easy to interpret this measure. The shortcoming of the method is that DARP method is based on the non-compensatory approach, so we ignore the fact that the potential surplus of one value is compensated in any way with the option values of other criteria.

Please note that from the technical viewpoint, other MCDA methods could be, at least theoretically, used to analyse the problem under consideration, as it is a typical problem of ranking alternatives [37]. Yet, the presence of individual aspiration levels, that should be taken into consideration for normalising the performances of individual 
alternatives only, makes DARP particularly advantageous. Other methods, such as those operating with pairwise comparisons (e.g., AHP, PROMETHEE) would be vulnerable for the by-effects resulting from the inclusion of all individual reference alternatives into the set of all alternatives under consideration. When they are used, the rank reversals may easily occur if some (even inferior) alternatives are added or removed in pairwise methods $[1,45]$.

The other goal of the paper was to verify the proposed framework by implementing DARP for measuring sustainable development. An example conducted in the context of smart growth confirms and illustrates the effectiveness of the proposed method. It shows that using simultaneously different reference points that are scaled and measured employing a single index with a common reference to the vector of worst possible performances allows us to consider the situation and performance of the alternatives in-depth, and to confront their objective performance with some external requirements. The motivation for this example comes from an examination of rankings obtained by different reference points. Specifically, what is the effect of the choice of the reference point (EU target, national target) on the final ranking? We showed that the choice of reference point influences the structure of the interactive solution. The proposed method is simple and transparent and can be successfully used also in other applications.

In further research, the theoretical framework of DARP needs to be investigated. Also, the proposed method should be used in other applications for further verification of its effectiveness. Especially, the variants of DARP for fully and non-compensatory realities may be proposed and assessed. We are also interested in the application of DARP technique to support the negotiation process. In [44], three MCDM methods (TOPSIS, VIKOR, BIPOLAR) based on reference points were analysed as "a tool that helps negotiators in the elicitation of preferences and evaluation of negotiation offers". In other papers $[35,36]$, the problem of evaluation negotiation offers from the outside of feasible negotiation space are considered, which is similar to the problem of evaluating the countries that outperform the external targets (like Sweden). Thus, to handle various aspiration reference points involved in the negotiation problem, the proposed DARP method could also be considered.

Let us notice that the setting of aspiration reference points impacts the final ranking negotiation offers. Therefore, determining the aspiration of the reference points is a critical issue when applying the proposed methodology. From a behavioural perspective, the choice of aspiration reference point can affect the negotiation scoring system, and, consequently, influence the negotiators' behaviour during the negotiation process and its outcomes. It is like the concept of anchoring point, which has been widely discussed in the behavioural negotiation literature [4]. A more detailed discussion about the proper settlement of reference points for negotiation issues in the context of heuristic will also be provided in the future. The other problem is evaluating the usability of the proposed technique with other methods of normalisation or distance measure. 


\section{Acknowledgements}

This work was supported by the grant from The Polish National Science Center (2016/21/B/HS4/01583).

\section{References}

[1] AIRES R.F.F., FERREIRA L., The rank reversal problem in multi-criteria decision making: a literature review, Pesq. Oper., 2018, 38 (2), 331-362.

[2] BANDURA R., Composite Indicators and Rankings. Inventory 2011, Technical report, Office of Development Studies, United Nations Development Programme (UNDP), New York 2011.

[3] BAStER N., Measuring Development. The Role and Adequacy of Development Indicators, Frank Cass, London 1972.

[4] Bazerman M., Moore D.A., Judgment in Managerial Decision Making, Wiley, 2009.

[5] BehZAdian M., OtAGHSARA S.K., YAZDANi M., IgnatiUs J., A state-of-the-art survey of TOPSIS applications, Exp. Syst. Appl., 2012, 39, 13051-13069.

[6] Burns T., Roszkowska E., Social Theory of Choice. From Simon and Kahneman-Tversky to GGT modeling of socially contextualized decision situations, Opt. Econ. Studies, 2008, 3 (39), 3-44.

[7] BÜYÜKÖZKAN G., KARABULUT Y., Sustainability performance evaluation. Literature review and future directions, J. Environ. Manage., 2018, 217, 253-267.

[8] Chatterjee P., ChaKraborty S., A comparative analysis of VIKOR method and its variants, Dec. Sci. Lett., 2016, 5, 469-486.

[9] Diaz-Balteiro L., GonZÁlez-Pachón J., Romero C., Measuring systems sustainability with multi-criteria methods. A critical review, Eur. J. Oper. Res., 2017, 258 (2), 607-616.

[10] Di Domizio M., The competitive balance in the Italian football league. A taxonomic approach, wpcomunite.it, Department of Communication, University of Teramo, 2008, 48.

[11] European Commission, Europe 2020, A strategy for smart, sustainable and inclusive growth, Brussels 2010, http.//ec.europa.eu/eu2020/pdf/COMPLET\%20EN\%20BARROSO $\% 20 \% 20 \% 20007 \% 20-\% 20$ Europe \%202020\%20-\%20EN\%20version.pdf (accessed 20 November 2019).

[12] EUROSTAT, Europe 2020 indicators - country profiles, 2019, https.//ec.europa.eu/eurostat/statisticsexplained/index.php?title=Europe_2020_indicators_-_country_profiles\#Articles_by_country (accessed 20 November 2019).

[13] Multiple Criteria Decision Analysis. State of the Art Surveys, J. Figueira, S. Greco, M. Ehrgott (Eds.), Springer, New York 2005.

[14] GÓRECKA D., Using Bipolar Mix in the process of selecting projects applying for co-financing from the European Union, [In:] L.Z. Stirn, M.K. Borštnar, J. Žerovnik, S. Drobne (Eds.), Proc. SOR 2017, 14th International Symposium on Operational Research, Bled, Slovenia, September 27-29, 2017, Slovenian Society Informatika, Section for Operational Research, Ljubljana 2017, 174-179.

[15] GóRECKA D., Bipolar Mix - a method for mixed evaluations and its application to the ranking of European projects, Mult. Crit. Dec. Making, 2017, 12, 36-48.

[16] GóRECKA D., Multi-criteria support for selecting European projects, TNOiK, Toruń 2009 (in Polish).

[17] Greco S., IshizAKa A., TASIOU M., TORRISI G., On the methodological framework of composite indices. A review of the issues of weighting, aggregation, and robustness, Soc. Ind. Res., 2019, 141, 61-94.

[18] Hellwig Z., Application of the taxonomic method to the typological division of countries due to the level of their development and the structure of qualified personnel, Stat. Rev., 1968, 4, 307-327, (in Polish).

[19] Hellwig Z., On the optimal choice of predictors, [In:] Z. Gostkowski (Ed.), Towards a System of Human Capital Resources Indicators for Less Developed Countries, Papers Prepared for a UNESCO Research Project, Ossolineum, Polish Academy of Sciences, Wrocław 1972, 115-134. 
[20] HuAng I.B., Keisler J., LinKOv I., Multi-criteria decision analysis in environmental sciences. Ten years of applications and trends, Sci. Total Environ., 2011, 409, 3578-3594.

[21] Hwang C.L., Yoon K., Multiple Attribute Decision Making Methods and Applications, Springer, Berlin 1981.

[22] IshiZaKa A., Nemery P., Multi-Criteria Decision Analysis. Methods and Software, Wiley, 2013.

[23] KonarZeWSKa-GubaŁA E., Multicriteria decision analysis with bipolar reference system. Theoretical model and computer implementation, Arch. Aut. Telemech., 1987, 32 (4), 289-300.

[24] KonarZeWSKA-GubaŁa E., Multiple criteria company benchmarking using the bipolar method, [In:] T. Trzaskalik, J. Michnik (Eds.), Multiple objective and goal programming. Recent developments, Springer, Heidelberg 2002, 338-350.

[25] Konarzewska-GubaŁA E., Bipolar. Multiple Criteria Decision Aid Using Bipolar Reference System, LAMSADE, Cahier et Documents, 56, Paris 2009.

[26] Maggino F., Complexity in Society. From Indicators Construction to Their Synthesis, Springer, 2017.

[27] Mazziotta M., PAREto A., Synthesis of indicators. The composite indicators approach, [In:] F. Maggino (Ed.), Complexity in Society. From Indicators Construction to Their Synthesis, Soc. Ind. Res. Ser., 70, Springer, 2017, 159-191.

[28] Melamed C., Bergh G., Sustainable Development Goals and Targets. Options for Differentiating between Countries, Overseas Development Institute, London 2014, https://www.odi.org/sites/odi. org.uk/files/odi-assets/publications-opinion-files/9047.pdf

[29] Miola A., Schiltz F., Measuring sustainable development goals performance. How to monitor policy action in the 2030 Agenda implementation?, Ecol. Econ., 2019, 164, 106373.

[30] OECD, Measuring Distance to the SDG Targets 2019. An Assessment of Where OECD Countries Stand, OECD Publishing, Paris 2019, https.//doi.org/10.1787/a8caf3fa-en

[31] OpRICOVIC S., TZENG G.H., Compromise solution by MCDM methods. A comparative analysis of VIKOR and TOPSIS, Eur. J. Oper. Res., 2004, 156 (2), 445-455.

[32] PAWLAS I., Economic picture of the enlarged European Union in the light of taxonomic research, Proc. MAC-EMM 2016, 5-6 August, Prague 2016.

[33] Reiff M., Surmanová K., BalcerzaK A.P., PietrzaK M.B., Multiple criteria analysis of European Union agriculture, J. Int. Studies, 2016, 9 (3), 62-74.

[34] Roszkowska E., Filipowicz-Chомко M., Measuring sustainable development in the education area using multi-criteria methods. A case study, Centr. Eur. J. Oper. Res., 2019, 28, 1219-1241.

[35] RoszKowsKa E., WACHOWICZ T., Application of fuzzy TOPSIS to scoring the negotiation offers in ill-structured negotiation problems, Eur. J. Oper. Res., 2015, 242, 920-932.

[36] RoszkowsKa E., WACHOWICZ T., Scoring the negotiation offers from the outside of the feasible negotiation space, Research Papers of Wroclaw University of Economics, 2016, 385, 201-209 (in Polish).

[37] Roy B., Multicriteria Methodology for Decision Aiding, Kluwer Academic Publisher, 1996.

[38] SimOn H.A., Models of Man, Macmillan, New York 1957.

[39] TAluKder W., HiPel K.W., VAN LOON G.W., Developing composite indicators for agricultural sustainability assessment. Effect of normalization and aggregation techniques, Resources, 2017, 6 (4), 66.

[40] Multi-criteria decision support. Methods and applications, T. Trzaskalik (Ed.), PWE, Warsaw 2014 (in Polish).

[41] Trzaskalik T., Sitarz S., Dominiak C., Bipolar method and its modifications, Centr. Eur. J. Oper. Res., 2019, 27 (3), 625-651.

[42] Tzeng G.H., Huang J.J., Multiple Attribute Decision Making. Methods and applications, Chapman and Hall, CRC, 2011.

[43] United Nations, Transforming our World. The 2030 agenda for sustainable development, 2015, A/RES /70/1https.//sustainabledevelopment.un.org/content/documents/21252030\%20Agenda $\% 20$ for\% 20Sustainable\%20Development\%20web.pdf (accessed 20 November 2019). 
[44] Wachowicz T., Brzostowski J., Roszkowska E., Reference points-based methods in supporting the evaluation of negotiation offers, Oper. Res. Dec., 2012, 4, 121-137.

[45] Wang Y.M., LuO Y., On rank reversal in decision analysis, Math. Comp. Model., 2009, 49 (5-6), $1221-1229$.

[46] WiERZBICKI A.P., The use of reference objectives in multiobjective optimization, Lect. Notes Econ. Math. Syst., 1980, 177, 468-486.

[47] YAZDANi M., GRAEML F.R., VIKOR and its applications. A state-of-the-art survey, Int. J. Strat. Dec. Sci., 2014, 5 (2), 56-83.

[48] Roszkowska E., Filipowicz-Сномко M., Measuring sustainable development using an extended Hellwig method. A case study of education, Soc. Ind. Res., 2020, https.//doi.org/10.1007/s11205-02002491-9. 